\title{
Electrophysiological characteristics and anatomical differentiation of epileptic and non-epileptic myoclonus
}

\author{
Mohammad Abu-Hegazy, Azza Elmoungi, Eman Eltantawi and Ahmed Esmael ${ }^{*}$ (1)
}

\begin{abstract}
Background: Electrophysiological techniques have been used for discriminating myoclonus from other hyperkinetic movement disorders and for classifying the myoclonus subtype. This study was carried out on patients with different subtypes of myoclonus to determine the electrophysiological characteristics and the anatomical classification of myoclonus of different etiologies. This study included 20 patients with different subtypes of myoclonus compared with 30 control participants. Electrophysiological study was carried out for all patients by somatosensory evoked potential (SSEP) and electroencephalography (EEG) while the control group underwent SSEP. SSEP was evaluated in patients and control groups by stimulation of right and left median nerves.

Results: This study included 50 cases with myoclonus of different causes with mean age of $39.3 \pm 15.7$ and consisted of 23 males and 27 females. Twenty-nine (58\%) of the patients were epileptics, while 21 (42\%) were non-epileptics. Cases were classified anatomically into ten cases with cortical myoclonus (20\%), 12 cases with subcortical myoclonus (24\%), and 28 cases with cortical-subcortical myoclonus (56\%). There was a significant difference regarding the presence of EEG findings in epileptic myoclonic and non-epileptic myoclonic groups $(P=0.005)$. Also, there were significant differences regarding P24 amplitude, N33 amplitude, P24-N33 peak-to-peak complex amplitude regarding all types of myoclonus. Primary myoclonic epilepsy (PME) demonstrated significant giant response, juvenile myoclonic epilepsy (JME) demonstrated no enhancement compared to controls, while secondary myoclonus demonstrated lower giant response compared to PME.
\end{abstract}

Conclusion: Somatosensory evoked potential and electroencephalography are important for the diagnosis and anatomical sub-classification of myoclonus and so may help in decision-making regarding to the subsequent management.

Keywords: SSEP, Epilepsy, Myoclonus, EEG

\section{Background}

Myoclonus is a hyperkinetic movement disorder characterized by sudden, brief, involuntary shock-like movements affecting a single or group of muscles [1-3]. It can be accompanied by bursts of muscle contraction (positive myoclonus) or sudden interruption of muscle contraction (negative myoclonus) [4].

\section{*Correspondence: deltaneuro@yahoo.com}

Department of Neurology, Faculty of Medicine, Mansoura University,

El-gomhoria Street, P.O. Box 35516, Mansoura, Egypt
Myoclonus can be subdivided according to etiology into primary or secondary. Primary can be classified into physiological or normal myoclonus, essential or idiopathic myoclonus (hereditary), and epileptic myoclonus; while secondary myoclonus is symptomatic myoclonus secondary to an underlying disorder [5]. Moreover, myoclonus can arise from several levels in the nervous system and can be subdivided by the anatomical origin into the following: cortical, subcortical, spinal, and peripheral myoclonus [6]. 
The main clinical characteristics demarcating myoclonus from other movement disorders are its rapid onset, brief duration, and the single-event type of muscle activation. Myoclonus can happen spontaneously or during movement (action myoclonus) or can be initiated by external stimuli (reflex myoclonus) [7]. Cortical myoclonus is more common in the hands and face and mainly precipitated by tactile stimuli. While brainstem reflex myoclonus affects the arms bilaterally. Spinal myoclonus tends to present as unilateral arrhythmic jerking in the arm and/or trunk, while propriospinal myoclonus characterized by jerking of the trunk and abdomen [8].

Recognition of myoclonus and determination of the underlying etiology remains challenging [9].

The presence of associated neurological signs usually indicates symptomatic myoclonus. Meanwhile, sudden or rapid onset points to a toxic, infectious, or metabolic etiology. More gradual onset may indicate a degenerative or metabolic disorder [10]. The degree to which myoclonus improves with treatment depends on the underlying etiology. Certain types of myoclonus may be secondary to potentially treatable etiologies as an inflammatory disorder or a metabolic disturbance [11].

The differentiation of myoclonic jerks from other hyperkinetic movement disorders sometimes may be difficult [12]. Electrophysiological techniques have been used for discriminating myoclonus from other hyperkinetic movement disorders and for classifying the myoclonus subtype [13, 14]. EEG is helpful for the diagnosis of epileptic myoclonus [15].

Neurophysiologic studies aid in the confirmation and classification of clinical diagnoses as well as the understanding of underlying physiological mechanisms [16]. Based on electro-diagnostic research, the anatomical categorization has been revised in recent years. Cortical, subcortical, and segmental myoclonus are the most common anatomical categories, with cortical-subcortical myoclonus being added as a fourth category by certain authors. Cortical myoclonus is the most common cause of positive electro-diagnostic criteria. Thus, a large somatosensory evoked response preceding the jerks may indicate a cortical myoclonus generator, whereas subcortical myoclonus lacks these traits [17].

The aim of this study is to identify the electrophysiological characteristics and the anatomical classification of myoclonus of different causes.

\section{Methods \\ Participants}

The sample of this study consists of 50 patients with myoclonus of different etiologies, admitted to the neurology department during the period from June 2018 to December 2019. Patients were studied after obtaining written informed consent. The control group consisted of 30 healthy individuals, age and sex-matched with patients with myoclonus, with no psychiatric comorbidities to exclude psychological myoclonus.

\section{Classification of patients}

Myoclonus can occur due to a variety of etiologies and pathophysiologic mechanisms in each clinical category. As a result, clinical-etiologic category delineation is not always precise. Furthermore, several types of myoclonus can be caused by the same etiology, and some individuals may experience more than one type of myoclonus. Patients were classified according to Marsden et al. who described the numerous etiologies of myoclonus into four major categories (physiologic, essential, epileptic, and secondary) [18].

\section{Electrophysiological study}

Studied patients were subjected to complete history taking, medical and neurological examination of patients. Subsequently, patients underwent neurophysiological studies including somatosensory evoked potential and electroencephalogram [19]. SSEPs were done for the control group obtained by right and left median nerve stimulation and EEG for comparison with the patients.

\section{Somatosensory evoked potential}

The stimulating device is Nihon Kohden MEB-9400 K, made in Japan. Manufactured Date: 2006-01-01. Serial Number: 00029. The electrode placement: the active (negative) electrodes: $\mathrm{CPc}(\mathrm{Cp} 3 / \mathrm{Cp} 4)$.

The reference (positive) electrodes: Fpz or linked A1 or A2. The ground electrode was strapped around the ipsilateral forearm. The amplifier sensitivity: $10-20 \mu \mathrm{V}$. The amplifier filter: hi 100HZ, low $2 \mathrm{HZ}$.

Technique: SSEP testing was performed in a quiet semi-darkened room, the room temperature was kept constant by air conditioning, and the test was performed with the subject (patients or control) sitting comfortably on a chair. Median nerve stimulation (right and left) for each subject was done with electrical square wave pulses of $0.2 \mathrm{~ms}$ duration applied at a rate of $5 \mathrm{HZ}$ with cathode proximally. Adjustment of the intensity of the stimulus was made for the production of minimal twitches of the thumb (1-2 cm thumb movement). 500 stimuli were applied and the recording electrode picked up the responses. When two reproducible SEPs responses were displayed on the screen, the data were accepted for analysis. An experienced neurophysiologist (MA) evaluated the findings and determined if the results were matched with myoclonus and its subtype. 


\section{Electroencephalogram (EEG)}

Recordings were performed using EB Neuro Basis BE Hardware (Firenze, Italy) and Galileo Software (Firenze, Italy) for EEG data acquisition and review 2010. Photic stimulation and hyperventilation each were done for one minute. The subjects were awake with their eyes closed for 10 min during EEG Recording. The EEGs were analyzed afterward and saved on specific EEG papers. The standard 10-20 electrode placement system was used.

\section{Statistical analysis}

The collected data were analyzed using SPSS Prism created by IBM, Chicago, IL, USA version 20, 2013 for Windows. Qualitative data were estimated as number and percent and the quantitative data were estimated as mean \pm SD.

Different subtypes of myoclonus groups were compared together and the control group by utilizing the Chisquare test. Student t-test was utilized for comparison between two groups while F-test (one-way Anova) was utilized for comparison between more than two groups. $P<0.05$ was considered to be statistically significant.

\section{Results}

This study included 50 patients with myoclonus of different etiologies with average age of $39.30 \pm 15.73$ and consisted of 23 male and 27 female patients. Twentynine $(58 \%)$ of the patients were epileptics, while 21 (42\%) were non-epileptics. The patients were classified clinically into 19 patients JME (38\%), 10 patients progressive myoclonic epilepsy (20\%), 21 patients with secondary myoclonus (42\%): (2 post-hypoxic myoclonus (4\%), 2 post-ischemic stroke myoclonus (4\%), 6 myoclonus secondary to hepatic condition (12\%), 6 myoclonus secondary to chronic kidney disease (12\%), 5 drug-induced myoclonus(10\%) (Table 1). Cases of drug-induced myoclonus were 2 cases of opiate addicts,

Table 1 Classifications of patients and types of myoclonus $(N=50)$

\begin{tabular}{lc}
\hline Myoclonus types & Number (\%) \\
\hline 1-Epileptic myoclonus & $19(38 \%)$ \\
Juvenile myoclonic epilepsy & $10(20 \%)$ \\
Progressive myoclonic epilepsy & \\
2-Non-epileptic myoclonus & $2(4 \%)$ \\
Post-hypoxic myoclonus & $2(4 \%)$ \\
Post-ischemic stroke myoclonus & $6(12 \%)$ \\
Hepatic & $6(12 \%)$ \\
Chronic kidney disease & $5(10 \%)$ \\
Drug-induced myoclonus & $50(100 \%)$ \\
Total number & \\
\hline
\end{tabular}

one PD patient treated with amantadine, one case was treated with TCA, and one case was treated with lithium. The drug-induced myoclonus occurred after the onset of these medications and improved after its withdrawal.

Total patients with myoclonus compared with healthy controls showed no statistically significant difference regarding their age. While there was statistical significant increase of the amplitudes of right and left median nerve SSEP P24 $(P=0.006),(P=0.001)$, N33 $(P=0.033), \quad(P=0.001)$, P24-N33 peak-to-peak complex $(P=0.004),(P=0.001)$, respectively, compared with healthy controls. However, there were no statistically significant differences in the amplitudes of right and left median nerve SSEP (Table 2).

Epileptic myoclonus includes JME and PME, while, non-epileptic myoclonus includes secondary myoclonus (post-hypoxic, post-ischemic stroke, secondary to hepatic condition, secondary to chronic kidney disease and drug-induced). There was a statistically significant higher age in non-epileptic myoclonus compared to epileptic myoclonus $(P<0.001)$. Regarding sex in the epileptic and epileptic groups of patients, there was no statistically significant difference $(P=0.179)$. Also, there were no statistically significant differences regarding right and left median nerve SSEP findings amplitude and latency of N20, P24, N33, P24-N33 complex. There were statistically significant differences in EEG findings between epileptic and non-epileptic myoclonus $(P=0.007)$, as most of cases with epileptic myoclonus showed spike/polyspike wave complex

Table 2 SSEP in patients and control groups

\begin{tabular}{|c|c|c|c|}
\hline & Patients $(N=50)$ & Control $(N=30)$ & $P$ \\
\hline Age & $39.30 \pm 15.73$ & $35.20 \pm 8.64$ & 0.137 \\
\hline \multicolumn{4}{|l|}{ Right median nerve } \\
\hline N20 amplitude & $1.94 \pm .71$ & $2.17 \pm .83$ & 0.184 \\
\hline N20 latency & $23.25 \pm .16$ & $23.27 \pm .15$ & 0.557 \\
\hline P24 amplitude & $8.27 \pm 13.67$ & $2.70 \pm .83$ & $0.006^{*}$ \\
\hline P24 latency & $25.08 \pm .49$ & $25.16 \pm .17$ & 0.245 \\
\hline N33 amplitude & $10.07 \pm 15.36$ & $3.97 \pm 1.27$ & $0.033^{*}$ \\
\hline N33 latency & $33.97 \pm .43$ & $34.08 \pm .20$ & 0.173 \\
\hline P24-N33 complex amp & $18.36 \pm 28.98$ & $5.78 \pm 1.98$ & $0.004^{*}$ \\
\hline \multicolumn{4}{|l|}{ Left median nerve } \\
\hline N20 amplitude & $1.95 \pm .72$ & $2.04 \pm .71$ & 0.570 \\
\hline N20 latency & $23.23 \pm .13$ & $23.23 \pm .15$ & 0.986 \\
\hline P24 amplitude & $8.16 \pm 11.48$ & $2.36 \pm .87$ & $0.001^{*}$ \\
\hline P24 latency & $25.03 \pm .45$ & $25.17 \pm .17$ & 0.058 \\
\hline N33 amplitude & $10.17 \pm 13.54$ & $3.54 \pm 1.25$ & $0.001^{*}$ \\
\hline N33 latency & $33.97 \pm .50$ & $34.08 \pm .19$ & 0.160 \\
\hline P24-N33 complex amp & $18.34 \pm 25.01$ & $5.70 \pm 2.00$ & $0.001^{*}$ \\
\hline
\end{tabular}


while, most of cases with non-epileptic myoclonus normal EEG findings were detected (Table 3).

There are statistically significant differences between different types of myoclonus (juvenile myoclonic epilepsy, progressive myoclonic epilepsy, and secondary myoclonus) regarding right and left P24 amplitudes $(P=0.049),(P=0.023)$, right and left N33 amplitudes $(P=0.042),(P=0.022)$ and right and left P24-N33 complex peak-to-peak amplitude $(P=0.045), \quad(P=0.022)$. There is a statistically significant EEG findings in the form of Spike/polyspike wave in cases with JME, postischemic stroke myoclonus, and post-hypoxic myoclonus $(P=0.024)$ (Table 4).

Patients were classified anatomically into 10 patients with cortical myoclonus (20\%), 12 patients with subcortical myoclonus (24\%) and 28 patients with corticalsubcortical myoclonus (56\%). There were statistically significant differences in cortical myoclonus group compared to control group regarding right and left P24 amplitude $(P<0.001)(P=0.041)$, right and left N33 amplitudes $(P=0.006)(P=0.041)$, right and left $\mathrm{P} 24-\mathrm{N} 33$ complex peak-to-peak amplitudes $(P<0.001),(P=0.040)$. In addition, there were statistically significant differences in subcortical myoclonus group compared to the control group regarding right and left P24 amplitude $(P<0.001)$, right and left N33 amplitudes $(P<0.001)$, right and left P24-N33 complex peak-to-peak amplitudes $(P<0.001)$. Moreover, there were statistically significant differences regarding right and left P24 amplitude $(P=0.004)$ $(P=0.034)$, right and left N33 amplitudes $(P=0.005)$, $(P=0.029)$, right and left $\mathrm{P} 24-\mathrm{N} 33$ complex peak-topeak amplitudes $(P=0.002),(P=0.024)$ in the cortical-subcortical group in comparison to control group. There was a statistically significant EEG findings in the form of Spike/polyspike wave in cases with cortical myoclonus compared with subcortical myoclonus $(P=0.005)$ (Table 5).

PME showed marked giant response, JME showed no enhancement in comparison to controls, secondary myoclonus showed giant response but of fewer values than PME in comparison to controls (Fig. 1A-C).

\section{Discussion}

Our study included 50 patients presented with myoclonus 23 males (46\%) and 27 females (54\%), in comparison to 30 control subjects 15 males $(50 \%)$ and 15 females (50\%). The age of patients ranged between 12 and 69 years with mean $39.30 \pm 15.73$.

Etiologic classification of myoclonus distinguishes four broad categories: physiologic, essential, epileptic,

Table 3 SSEP and EEG findings in epileptic and non-epileptic myoclonus

\begin{tabular}{|c|c|c|c|}
\hline & Epileptic myoclonus $(N=29)$ & Non-epileptic $(N=21)$ & $P$ value \\
\hline Age & $32.76 \pm 11.96$ & $48.33 \pm 16.08$ & $<0.001^{*}$ \\
\hline \multicolumn{4}{|l|}{ Sex } \\
\hline Male & 11 & 12 & \multirow[t]{2}{*}{0.179} \\
\hline Female & 18 & 9 & \\
\hline \multicolumn{4}{|l|}{ Right median nerve } \\
\hline N20 amplitude & $1.99 \pm .68$ & $1.87 \pm .75$ & 0.590 \\
\hline N20 latency & $23.24 \pm .17$ & $23.26 \pm .14$ & 0.792 \\
\hline P24 amplitude & $8.95 \pm 17.98$ & $7.34 \pm 1.86$ & 0.687 \\
\hline N24 latency & $25.08 \pm .39$ & $25.07 \pm .61$ & 0.924 \\
\hline N33 amplitude & $10.77 \pm 20.21$ & $9.11 \pm 2.05$ & 0.664 \\
\hline N33 latency & $33.86 \pm .27$ & $34.11 \pm .57$ & 0.070 \\
\hline P24-N33 complex amp & $19.72 \pm 38.16$ & $16.50 \pm 3.68$ & 0.655 \\
\hline \multicolumn{4}{|l|}{ Left median nerve } \\
\hline N20 amplitude & $1.97 \pm .73$ & $1.92 \pm .73$ & 0.835 \\
\hline N20 latency & $23.20 \pm .13$ & $23.26 \pm .13$ & 0.106 \\
\hline P24 amplitude & $8.56 \pm 15.07$ & $7.60 \pm 2.11$ & 0.739 \\
\hline P24 latency & $25.14 \pm .53$ & $24.88 \pm .25$ & 0.105 \\
\hline N33 amplitude & $10.75 \pm 17.78$ & $9.37 \pm 2.42$ & 0.681 \\
\hline N33 latency & $33.97 \pm .49$ & $33.96 \pm .53$ & 0.977 \\
\hline P24-N33 complex amp & $19.33 \pm 32.84$ & $16.97 \pm 4.46$ & 0.705 \\
\hline \multicolumn{4}{|l|}{ EEG findings } \\
\hline Spike/polyspike wave complex & 22 & 8 & \multirow[t]{2}{*}{$0.007^{*}$} \\
\hline Normal & 7 & 13 & \\
\hline
\end{tabular}


Table 4 SSEP in different myoclonic subgroups

\begin{tabular}{|c|c|c|c|c|c|c|c|c|}
\hline & $\begin{array}{l}\text { Juvenile } \\
\text { myoclonic } \\
\text { epilepsy } \\
(N=19)\end{array}$ & $\begin{array}{l}\text { Progressive } \\
\text { myoclonic } \\
\text { epilepsy } \\
(N=10)\end{array}$ & $\begin{array}{l}\text { Secondary } \\
\text { (post-hypoxic) } \\
\text { Lance-Adams } \\
\text { syndrome } \\
(N=2)\end{array}$ & $\begin{array}{l}\text { Secondary } \\
\text { (post-ischemic } \\
\text { stroke } \\
\text { myoclonus) } \\
(N=2)\end{array}$ & $\begin{array}{l}\text { Secondary } \\
\text { (hepatic) } \\
(N=6)\end{array}$ & $\begin{array}{l}\text { Secondary } \\
\text { (chronic } \\
\text { kidney) }(N=6)\end{array}$ & $\begin{array}{l}\text { Drug-induced } \\
\text { myoclonus } \\
(N=5)\end{array}$ & $P$ \\
\hline Age & $31.9 \pm 12.5$ & $34.4 \pm 11.6$ & $61 \pm 4.5$ & $56 \pm 3.4$ & $56.7 \pm 5.9$ & $59.3 \pm 7.4$ & $28.9 \pm 10.9$ & 0.13 \\
\hline N20 amplitude & $1.9 \pm 0.7$ & $2.1 \pm 0.6$ & $0.9 \pm 0.5$ & $2.8 \pm 0.7$ & $1.9 \pm 0.6$ & $1.9 \pm 0.8$ & $1.9 \pm 0.9$ & 0.63 \\
\hline N20 latency & $23.3 \pm .18$ & $23.2 \pm .12$ & $23 \pm 2.4$ & $23.4 \pm 1.6$ & $23.2 \pm 0.1$ & $23.3 \pm 0.1$ & $23.3 \pm 0.1$ & 0.22 \\
\hline P24 amplitude & $2.6 \pm 1.1$ & $20.9 \pm 27.5$ & $10.6 \pm 1.2$ & $8.5 \pm 0.6$ & $7.8 \pm 2.2$ & $6.7 \pm 1.6$ & $6.9 \pm 1.6$ & $0.04^{*}$ \\
\hline P24 latency & $25.2 \pm 0.2$ & $24.9 \pm 0.55$ & $24.4 \pm 2.3$ & $24.8 \pm 1.7$ & $25.5 \pm 0.8$ & $24.8 \pm 0.6$ & $24.9 \pm 0.2$ & 0.06 \\
\hline N33 amplitude & $3.7 \pm 1.4$ & $24.5 \pm 30.8$ & $11.4 \pm 1.3$ & $12.5 \pm 0.4$ & $9.5 \pm 2.1$ & $8.8 \pm 1.6$ & $8.2 \pm 2.1$ & $0.04^{*}$ \\
\hline N33 latency & $34.03 \pm 0.1$ & $33.54 \pm 0.18$ & $33.3 \pm 1.8$ & $35.6 \pm 1.9$ & $34.1 \pm 0.6$ & $34.1 \pm 0.6$ & $34 \pm 0.21$ & 0.14 \\
\hline $\begin{array}{l}\text { P24-N33 com- } \\
\text { plex amplitude }\end{array}$ & $6.2 \pm 2.5$ & $45.4 \pm 58.3$ & $22.1 \pm 1.2$ & $21 \pm 0.8$ & $17.7 \pm 4$ & $15.6 \pm 2.9$ & $15.1 \pm 3.6$ & $0.04^{*}$ \\
\hline N20 amplitude & $1.9 \pm 0.7$ & $2.01 \pm 0.7$ & $1.9 \pm 0.5$ & $1 \pm 0.3$ & $1.8 \pm 0.6$ & $2.3 \pm 0.9$ & $1.8 \pm 0.8$ & 0.7 \\
\hline N20 latency & $23.2 \pm 0.14$ & $23.1 \pm 0.11$ & $23.6 \pm 3.2$ & $23.4 \pm 0.7$ & $23.7 \pm 0.2$ & $23.3 \pm 0.1$ & $23.2 \pm 0.1$ & 0.29 \\
\hline P24 amplitude & $2.9 \pm 1.2$ & $19.4 \pm 22.5$ & $7.2 \pm 0.7$ & $8.4 \pm 0.5$ & $7.4 \pm 2.9$ & $7.1 \pm 2.6$ & $8.1 \pm 2.1$ & $0.02^{*}$ \\
\hline P24 latency & $25.1 \pm 0.1$ & $25.2 \pm 0.9$ & $24.9 \pm 3.2$ & $25.1 \pm 2.9$ & $24.9 \pm 0.3$ & $25 \pm 0.2$ & $24.7 \pm 0.2$ & 0.39 \\
\hline N33 amplitude & $4.1 \pm 1.2$ & $23.5 \pm 26.5$ & $9.6 \pm 0.9$ & $10.6 \pm 0.8$ & $9.1 \pm 2.8$ & $8.5 \pm 2.8$ & $10.1 \pm 2.7$ & $0.02^{*}$ \\
\hline N33 latency & $34.1 \pm 0.3$ & $33.6 \pm 0.57$ & $33.70 \pm 3.5$ & $33.8 \pm 2.2$ & $34.3 \pm .41$ & $33.7 \pm 0.4$ & $34 \pm 0.7$ & 0.07 \\
\hline $\begin{array}{l}\text { P24-N33 com- } \\
\text { plex amplitude }\end{array}$ & $6.9 \pm 2.3$ & $42.9 \pm 48.9$ & $16.8 \pm 2.4$ & $19 \pm 2.3$ & $16.5 \pm 5$ & $15.6 \pm 5.3$ & $18.2 \pm 4.2$ & $0.02^{*}$ \\
\hline $\begin{array}{l}\text { EGG spike/ } \\
\text { polyspike wave } \\
\text { complex }\end{array}$ & 12 (63.2\%) & $10(100 \%)$ & $2(100 \%)$ & $2(100 \%)$ & $4(66.6 \%)$ & $4(66.6 \%)$ & $2(40 \%)$ & $0.02^{*}$ \\
\hline
\end{tabular}

Table 5 SSEPs findings in different myoclonus subtypes according to anatomical classification

\begin{tabular}{|c|c|c|c|c|c|c|c|c|}
\hline & Cortical $(N=10)$ & Subcortical $(N=12)$ & $\begin{array}{l}\text { Cortical- } \\
\text { subcortical } \\
(N=28)\end{array}$ & Control $(N=30)$ & $P$ & $P 1$ & $P 1$ & P3 \\
\hline \multicolumn{9}{|l|}{ Right median nerve } \\
\hline N20 amplitude & $2.1 \pm 0.6$ & $1.9 \pm 0.7$ & $1.9 \pm 0.8$ & $2.2 \pm 0.8$ & 0.62 & 0.86 & 0.25 & 0.25 \\
\hline N20 latency & $23.2 \pm 0.1$ & $23.2 \pm 0.1$ & $23.3 \pm 0.2$ & $23.3 \pm 0.2$ & 0.28 & 0.08 & 0.536 & 0.96 \\
\hline P24 amplitude & $20.9 \pm 27.5$ & $7.2 \pm 1.9$ & $3.29 \pm 2.4$ & $2.7 \pm 0.8$ & $0.005^{*}$ & $<0.001^{*}$ & $<0.001^{*}$ & $0.004^{*}$ \\
\hline P24 latency & $24.8 \pm 0.6$ & $25.2 \pm 0.8$ & $25.1 \pm 0.3$ & $25.2 \pm 0.2$ & 0.3 & 0.14 & 0.864 & 0.61 \\
\hline N33 amplitude & $24.5 \pm 30.8$ & $9.7 \pm 1.8$ & $4.4 \pm 2.9$ & $3.9 \pm 1.3$ & $0.004^{*}$ & $0.006^{*}$ & $<0.001^{*}$ & $0.005^{*}$ \\
\hline N33 latency & $33.5 \pm 0.2$ & $34.1 \pm 0.5$ & $34.1 \pm 0.4$ & $34.1 \pm 0.2$ & $0.003^{*}$ & $<0.001^{*}$ & 0.89 & 0.87 \\
\hline P24-N33 complex amp & $45.4 \pm 58.3$ & $16.5 \pm 3.4$ & $7.7 \pm 5.2$ & $5.8 \pm 1.9$ & $0.004^{*}$ & $<0.001^{*}$ & $<0.001^{*}$ & $0.002^{*}$ \\
\hline \multicolumn{9}{|l|}{ Left median nerve } \\
\hline N20 amplitude & $2 \pm 0.7$ & $2.1 \pm 0.7$ & $1.9 \pm 0.7$ & $2.1 \pm 0.7$ & 0.76 & 0.89 & 0.25 & 0.48 \\
\hline N20 latency & $23.2 \pm 0.1$ & $23.3 \pm 0.1$ & $23.2 \pm 0.1$ & $23.2 \pm 0.2$ & 0.05 & 0.14 & 0.54 & 0.86 \\
\hline P24 amplitude & $19.4 \pm 22.5$ & $7.3 \pm 2.3$ & $3.3 \pm 1.9$ & $2.4 \pm 0.9$ & $0.002^{*}$ & $0.041^{*}$ & $<0.001^{*}$ & $0.034^{*}$ \\
\hline P24 latency & $25.2 \pm 0.9$ & $24.9 \pm 0.2$ & $25.1 \pm 0.1$ & $25.2 \pm 0.2$ & 0.39 & 0.83 & 0.86 & 0.11 \\
\hline N33 amplitude & $23.5 \pm 26.5$ & $8.8 \pm 2.69$ & $4.6 \pm 2.2$ & $3.5 \pm 1.3$ & $0.002^{*}$ & $0.041^{*}$ & $<0.001^{*}$ & $0.029^{*}$ \\
\hline N33 latency & $33.6 \pm 0.6$ & $33.97 \pm 0.52$ & $34.1 \pm 0.3$ & $34.1 \pm 0.2$ & 0.104 & $0.040^{*}$ & 0.895 & 0.746 \\
\hline P24-N33 complex amp & $42.9 \pm 49$ & $16.1 \pm 4.9$ & $7.9 \pm 4$ & $5.7 \pm 2$ & $0.002^{*}$ & $0.040^{*}$ & $<0.001^{*}$ & $0.024^{*}$ \\
\hline $\begin{array}{l}\text { EEG Spike/polyspike wave } \\
\text { complex }\end{array}$ & 10 (100\%) & $4(33.3 \%)$ & $18(64.3 \%)$ & 0 & $0.005^{*}$ & $<0.001$ & $<0.001$ & $<0.001$ \\
\hline
\end{tabular}



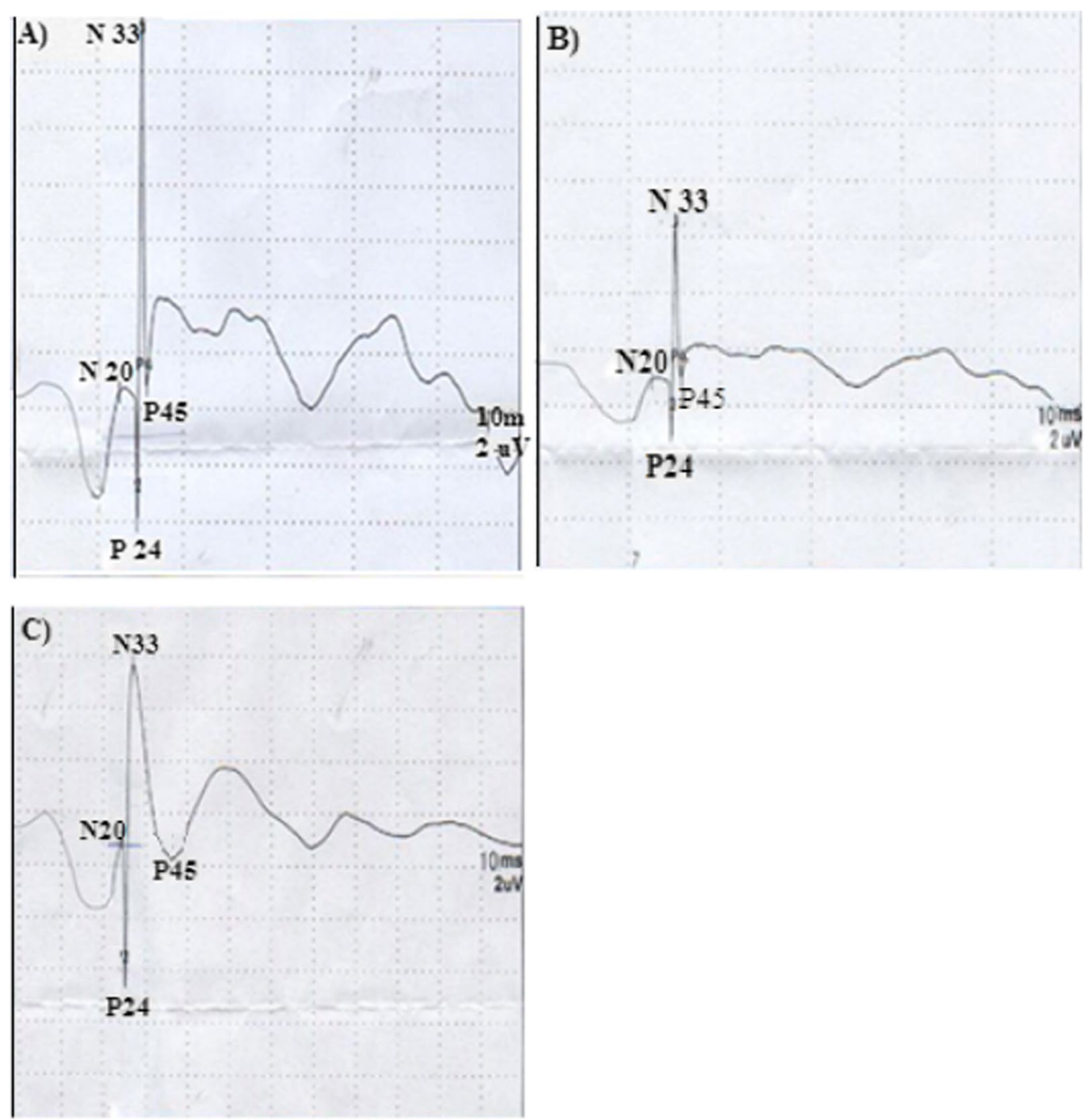

Fig. 1 EEG and SSEP in patients with different types of myoclonus. A SSEP in a patient with cortical myoclonus in case of PME showing giant response. B SSEP in a patient with cortical-subcortical myoclonus in case of JME showed no giant response in comparison with PME. C SSEP in a patient with subcortical myoclonus in case of secondary hepatic myoclonus showed giant response but of less values than PME

and secondary (or symptomatic) myoclonus [20]. Our study included 19 patients with JME (38\%), 10 patients with progressive myoclonic epilepsy (20\%) and 21 patients with secondary myoclonus. Out of our studied 50 patients with myoclonus, 29 patients were epileptic myoclonus, while 21 patients were non-epileptic myoclonus with no significant sex difference in both groups.

Regarding EEG findings in our studied patients with myoclonus; they showed statistically significant differences in regarding the abnormal EEG findings between epileptic and non-epileptic myoclonus $(P=0.007)$. Spike/polyspike wave complex was detected in 12 patients with JME out of 19 (63.2\%) and in all patients with PME (100\%) and this may be attributed to the fact that origin of myoclonus is cortical areas in epileptic patients and subcortical areas in non-epileptic patients. Eberhardt and Topka, and Caviness [17, 21], found a typical biphasic, often small $(5-20 \mu \mathrm{V})$ EEG transient (spike, polyspike) of 15-40 ms duration recorded in cortical myoclonus prior to the recorded movement response.

SSEP in our study comparing patients and control groups showed statistically significant increased amplitudes of right and left median nerves SSEP P24, N33 P24-N33 peak-to-peak complex indicating giant SEPs. Similarly, Hitomi et al. found an extremely large P24N33 component in patients with PME, the P24 and N35 peaks had large amplitudes $>5 \mathrm{Mv}$ [22]. The mean latency 
of N20 and N33 in our patients were prolonged in agreement of Storti et al. [23].

According to anatomical classification, our patients with cortical myoclonus demonstrate extremely enhanced SSEPs showing giant SSEP response more than other types of myoclonus. This is similar to Zutte et al. [9] and Kojovic et al. [24], who found that giant SSEP is present in cases with cortical myoclonus more than other types of myoclonus. Also, Eberhardt and Topka [17], found giant median nerve SSEP responses (P27/N35) following N20 response of normal size may be observed in some types of myoclonus. The majority of studies showed evidence of giant SSEPs only to median nerve stimulation; these giant SSEPs consisted of the increased amplitude of the components appearing after the N20, by the appearance of high amplitude complexes in the latency range of P25-N30 and P25-N30 complex [25]. These "giant" potentials can be seen in myoclonus of different origins such as PME, PHM (Lance-Adams syndrome), Alzheimer's disease, Creutzfeldt-Jakob disease, and metabolic encephalopathy [26].

According to anatomical classification, myoclonus was classified as cortical, subcortical and cortical-subcortical myoclonus [17]. Our patients were divided into 3 subtypes: cortical myoclonus 10 patients (20\%) (PME), subcortical myoclonus 12 patients (24\%) (secondary to hepatic condition and secondary to chronic kidney disease) and cortical-subcortical myoclonus 28 patients (56\%) (including JME, PHM, post-ischemic stroke myoclonus, and drug-induced). While the study of Zutt et al. [27], found that the initial diagnosis of cortical myoclonus in $55 \%$ of cases, subcortical myoclonus in $6.6 \%$ of cases, functional jerks in 33\% of cases and multiple myoclonus subtypes in $5 \%$ of cases.

Our study showed statistically significant difference in SSEPs findings in different myoclonus subtypes according to anatomical classification and the control group regarding right and left amplitude of P24, N33, P24-N33 peak-to-peak complex, all 3 subtypes showed enhancement of right and left amplitudes of P24, N33, P24-N33 complex in comparison to control group where cortical myoclonus showed marked enhancement followed by subcortical myoclonus followed by cortical-subcortical myoclonus.

Cortical myoclonus in our study shows markedly enhanced amplitudes of P24, N33 and P24-N33 complex amplitude $>20 \mu \mathrm{V}$ up to $45 \mu \mathrm{V}$. Zutt et al. [27], found that in cortical myoclonus giant SSEP is present and the P27 and N35 peaks had large amplitudes $>5 \mu \mathrm{V}$. Giant median nerve enlarged SSEP late responses following N20 were often more than tenfold enlarged or larger than $10 \mu \mathrm{V}$, can thus support the diagnosis of cortical myoclonus, but are not always present $[17,28]$. Ettinger and Weisbrot [29], found the enlarged cortical response of SSEPs in many cases.

All patients with cortical myoclonus in our study showed a positive EEG spike/polyspike wave complex (100\%). In studies of Eberhardt and Topka [17] and Cassim and Houdayer [30], the EEG discharge is usually smaller than focal epileptiform discharges. Biphasic, often small $(5-20 \mu \mathrm{V})$ EEG transient (spike, polyspike) of 15-40 ms duration can be recorded in cortical myoclonus prior to the recorded movement response. Its latency is about $20 \mathrm{~ms}$ for arm muscles and about $30 \mathrm{~ms}$ for leg muscles.

In cortical-subcortical myoclonus compared to the control group there was statistically significant higher amplitude in right and left amplitude of P24, N33, P24N33 and significant higher peak-to-peak complex. Also, cortical-subcortical myoclonus patients showed a positive EEG spike/polyspike wave complex in 18 out of 28 (64.3\%). Ettinger and Weisbrot [29] stated that SSEP cortical components are possibly enlarged and EEG showed generalized spike and wave complex.

In our study, subcortical myoclonus showed less enhanced amplitudes than cortical myoclonus in comparison to the control group, nearly in agreement with Zutt et al. [27] and Eberhardt and Topka [17] as their studies showed no giant SSEPs in subcortical myoclonus. In our study, 4 patients with subcortical myoclonus out of 12 (33.3\%) showed a positive EEG spike/ polyspike wave complex, while Ettinger and Weisbrot [29] found no consistent findings regarding EEG.

This study demonstrated the importance of somatosensory evoked potential and electroencephalography in the diagnosis and anatomical sub-classification of myoclonus and so may be of great value for the decision-making regarding the subsequent management. However, the main limitations of this study are small sized sample and the uses of interictal conventional EEG. So larger size samples were recommended for the future studies and long-term EEG with video monitoring for the patients could (probably) identify higher incidence of abnormalities, even with what may seem non-epileptic myoclonus.

\section{Conclusions}

Myoclonus is a symptom of different origins, which is often classified according to its anatomical origin. Electrophysiological testing is an important tool in the diagnosis and anatomical classification of myoclonus, and subsequently aiding in decision-making regarding therapeutic management. 


\section{Abbreviations}

EEG: Electroencephalography; JME: Juvenile myoclonic epilepsy; PHM: Posthypoxic myoclonus; PME: Primary myoclonic epilepsy; SSEP: Somatosensory evoked potential.

\section{Acknowledgements}

None.

\section{Authors' contributions}

AEs, MA and AEl made substantial contributions to the study and participated in its design, acquisition, analysis, and interpretation of data. EE, AEs and MA participated in the analysis and interpretations of the electrophysiological findings. All authors have read and approved the final manuscript.

\section{Funding}

This study received no funding.

\section{Availability of data and materials}

The datasets generated and analyzed during the current study are not publicly available due to institutional limitations, yet they are available from the corresponding author on reasonable request.

\section{Declarations}

\section{Ethics approval and consent to participate}

All procedures performed in this study were in accordance with the ethical standards of the institutional and/or national research committee and with the 1964 Helsinki declaration. Informed written consent was obtained from all individual participants included in the study. This study was approved by Mansoura Faculty of Medicine Institutional Research Board ("MFM-IRB"). Proposal Code: R.19.09.606-2019/09/04.

\section{Consent for publication}

Not applicable.

\section{Competing interests}

The authors declare that they have no competing interests.

Received: 17 June 2021 Accepted: 22 August 2021

Published online: 14 September 2021

\section{References}

1. Marras C, Lang A, van de Warrenburg BP, Sue CM, Tabrizi SJ, Bertram L, et al. Nomenclature of genetic movement disorders: recommendations of the international Parkinson and movement disorder society task force. Mov Disord. 2016;31:436-57.

2. Rossi M, Anheim M, Durr A, Klein C, Koenig M, Synofzik M, et al. The genetic nomenclature of recessive cerebellar ataxias. Mov Disord. 2018:33:1056-76.

3. Gupta N, Pandey S. Post-thalamic stroke movement disorders: a systematic review. Eur Neurol. 2018;79(5-6):303-14. https://doi.org/10.1159/ 000490070.

4. Park KD, Kim MK, Lee SJ. Negative myoclonus associated with pregabalin. Yeungnam Univ J Med. 2018;35(2):240-3. https://doi.org/10.12701/yujm. 2018.35.2.240.

5. Badheka R, Barad NK, Sankhla CS. Pediatric movement disorders. Neurol India. 2018;66(Supplement):S59-67.

6. Shibasaki $\mathrm{H}$, Thompson PD. Milestones in myoclonus. Mov Disord 2011;26:1142-8.

7. Vercueil L. Myoclonus and movement disorders. Neurophysiol Clin. 2006;36(5-6):327-31. https://doi.org/10.1016/j.neucli.2006.12.002.

8. Espay AJ, Chen R. Myoclonus. Continuum (Minneap Minn). 2013;19(5):1264-86. https://doi.org/10.1212/01.CON.0000436156.54532. $1 \mathrm{a}$.

9. Zutt R, van Egmond ME, Elting JW, van Laar PJ, Brouwer OF, Sival DA, et al. A novel diagnostic approach to patients with myoclonus. Nat Rev Neurol. 2015;11:687-97. https://doi.org/10.1038/nrneurol.2015.198.
10. Borg M. Symptomatic myoclonus. Neurophysiol Clin. 2006;36(5-6):309-18.

11. Mills K, Mari Z. An update and review of the treatment of myoclonus. Curr Neurol Neurosci Rep. 2015;15(1):512.

12. van Egmond ME, Elting JW, Kuiper A, Zutt R, Heineman KR, Brouwer OF, et al. Myoclonus in childhood-onset neurogenetic disorders: the importance of early identification and treatment. Eur J Paediatr Neurol. 2015;19:726-9.

13. Beudel M, Zutt R, Meppelink AM, Little S, Elting JW, Stelten BML, Edwards M, Tijssen MAJ. Improving neurophysiological biomarkers for functional myoclonic movements. Parkinsonism Relat Disord. 2018;51:3-8. https:// doi.org/10.1016/j.parkreldis.2018.03.029.

14. Erro R, Bhatia KP, Edwards MJ, Farmer SF, Cordivari C. Clinical diagnosis of propriospinal myoclonus is unreliable: an electrophysiologic study. Mov Disord. 2013;28(13):1868-73.

15. Caviness JN, Brown P. Myoclonus: current concepts and recent advances. Lancet Neurol. 2004;3(10):598-607.

16. Shibasaki H. Neurophysiological classification of myoclonus. Neurophysiol Clin. 2006;36(5-6):267-9. https://doi.org/10.1016/j.neucli.2006.11.004.

17. Eberhardt O, Topka H. Myoclonic disorders. Brain Sci. 2017;7(8):103. https://doi.org/10.3390/brainsci7080103.

18. Marsden CD, Hallett M, Fahn S. The nosology and pathophysiology of myoclonus. In: Marsden CD, Fahn S, editors. Movement disorders. London: Butterworths; 1982. p. 196.

19. Aminoff MJ. Aminoff's Electrodiagnosis in clinical neurology. In: Aminoff MJ, editor. Electroencephalography: general principles and clinical applications. Amsterdam: Elsevier Health Sciences; 2012. p. 37-165.

20. Zandbergen EG, Hijdra A, de Haan RJ, van Dijk JG, de Ongerboer Visser BW, et al. Interobserver variation in the interpretation of SSEPs in anoxicischaemic coma. Clin Neurophysiol. 2006;117(7):1529-35. https://doi.org/ 10.1016/j.clinph.2006.03.018.

21. Caviness JN. Treatment of myoclonus. Neurotherapeutics. 2014;11(1):188200. https://doi.org/10.1007/s13311-013-0216-3.

22. Hitomi T, Ikeda A, Matsumoto R, Kinoshita M, Taki J, Usui K, et al. Generators and temporal succession of giant somatosensory evoked potentials in cortical reflex myoclonus: epicortical recording from sensorimotor cortex. Clin Neurophysiol. 2006;117(7):1481-6. https://doi.org/10.1016/j. clinph.2006.03.029.

23. Storti SF, Del Felice A, Canafoglia L, Formaggio E, Brigo F, Alessandrini $F$, et al. Neurophysiological and BOLD signal uncoupling of giant somatosensory evoked potentials in progressive myoclonic epilepsy: a case-series study. Sci Rep. 2017;7:44664.

24. Kojovic M, Cordivari C, Bhatia K. Myoclonic disorders: a practical approach for diagnosis and treatment. Ther Adv Neurol Disord. 2011;4(1):47-62.

25. Anzellotti F, Onofrj M, Bonanni L, Saracino A, Franciotti R. Giant early components of somatosensory evoked potentials to tibial nerve stimulation in cortical myoclonus. Neurolmage Clin. 2016;12:212-8.

26. Cruccu G, Aminoff M, Curio G, Guerit J, Kakigi R, Mauguiere F, et al. Recommendations for the clinical use of somatosensory-evoked potentials. Clin Neurophysiol. 2008;119(8):1705-19.

27. Zutt R, Elting JW, van Zijl JC, van der Hoeven JH, Roosendaal CM, Gelauff $J M$, et al. Electrophysiologic testing aids diagnosis and subtyping of myoclonus. Neurology. 2018. https://doi.org/10.1212/WNL.0000000000 004996.

28. Shibasaki H, Hallett M. Electrophysiological studies of myoclonus. Muscle Nerve. 2005;31(2):157-74.

29. Ettinger $A B$, Weisbrot DM. Neurologic differential diagnosis: a case-based approach. In: Ramani V, Friedman DE, Songhorian M, editors. Myoclonus. Cambridge: Cambridge University Press; 2014. p. 740-58.

30. Cassim F, Houdayer E. Neurophysiology of myoclonus. Neurophysiol Clin/ Clin Neurophysiol. 2006;36(5):281-91.

\section{Publisher's Note}

Springer Nature remains neutral with regard to jurisdictional claims in published maps and institutional affiliations. 